\title{
Anticancer effects of retinoic acid and arsenic trioxide: The other side of the moon
}

\author{
Ruohan Zheng ${ }^{1, *}$, Qiuyun $\mathrm{Liu}^{2, *}$ \\ ${ }^{1}$ School of Chemistry, Sun Yat-sen University, Guangzhou 510275, China \\ ${ }^{2}$ School of Life Sciences, Sun Yat-sen University, Guangzhou 510275, China
}

${ }^{*}$ Corresponding author: Ruohan Zheng, School of Chemistry, Sun Yat-sen University, Guangzhou 510275, China. E-mail: 1065780699@qq.com; Qiuyun Liu, Ph.D, School of Life Sciences, Sun Yat-sen University, Guangzhou 510275, China. E-mail: 1sslqy@mail.sysu.edu.cn

\begin{abstract}
:
It was proposed that carcinogenesis can be resulted from the local buildup of strong acids such as $\mathrm{HCl}$. Cancer cells may overproduce weak or moderate organic acids such as oxalate to counteract strong acids, whereas insoluble and rigid calcium oxalate causes organ failure and death. Weak acids such as retinoic acid and arsenous acid, can work in a similar fashion and solubilize insoluble salts, therefore boasting cancer-protecting effects.
\end{abstract}

Keywords: anticancer effect; retinoic acid; arsenic trioxide; mechanism; arsenous acid 
It has been postulated that the local buildup of strong acids such as $\mathrm{HCl}$, mediated by hydrogen bond donors and acceptors and basic amino acids, triggers carcinogenesis $^{1,2}$. Cancer cells may overproduce organic acids such as oxalate to antagonize $\mathrm{HCl}$, and subsequent formation of insoluble and rigid salts such as calcium oxalate is stressful to cells. Retinoic acid and arsenous acid as weak acids can counteract strong acids directly for cancer protection.

Vitamin A, also known as retinol, is a type of fat-soluble vitamin with similar structure to carotene, including vitamin A1 and vitamin A2. It is first oxidized into retinal in the body and then further oxidized into retinoic acid. It has been noticed that the content of retinoic acid is closely related to tumor cell proliferation since the 1920s. After a long-time study, it has been found that retinoid compounds have effects on inducing differentiation and chemoprophylaxis. Extensive research has indicated that the regulation of gene expression by retinoic acid is direct rather than the result of inhibition of cell proliferation. In the cell, the C-myc gene encodes a DNA binding protein and initiates cell proliferation with growth factors. In vitro experiments have shown that retinoic acid can reduce the expression of $\mathrm{C}$-myc and at the same time increase the expression of CDKs inhibitor P27, thereby inducing the differentiation and apoptosis of small cell lung cancer cells ${ }^{3}$. Retinoic acid also inhibits the activity of telomerase $\mathrm{e}^{4}$, and telomerase is a specific marker of tumor cells.

Early in 1996, there was a report about arsenic trioxide in the treatment of leukemia ${ }^{5}$. After emergence of the chemical formulation of arsenic trioxide ATO, it was approved by the US FDA (Trisenox ${ }^{\circledR}$ ) for the treatment of acute pro-myelocytic leukemia (APL) in $2000^{6}$. APL is a unique subtype of acute myeloid leukemia, which is characterized by a specific chromosome translocation $\mathrm{t}(15 ; 17)$ and the expression of PML-RAR $\alpha$ fusion protein, which can block cell differentiation and inhibit apoptosis ${ }^{7}$. Arsenic Trioxide is dissolved in saline and administered as a dilute solution of aqueous arsenous acid, and previous study in vitro suggested that arsenic trioxide can induce apoptosis in NB4 cell line (a cell line with typical APL characteristics) and retinoic acid resistant APL cell line ${ }^{8,9}$. Arsenic trioxide induces molecular remission and prolongs survival in a high proportion of APL patients when used as a single agent ${ }^{10}$, and it can also act synergistically with ATRA (all trans retinoic acid $)^{11}$ to induce degradation of an oncoprotein that drives APL. Both arsenic trioxide and ATRA have the characteristic of degrading PML-RAR $\alpha$ protein, but arsenic trioxide targets the PML moiety of PML-RARA $\alpha$ protein where it can induce sumoylation of specific cysteine residues and stimulate proteasome-mediated degradation of the oncoprotein, while ATRA targets the RAR $\alpha$ moiety of PML/RARA $\alpha^{12}$. Therefore, there is no competition between arsenic trioxide and ATRA. In vitro study suggested that the combined effect of arsenic trioxide and ATRA on NB4-As cells has shown faster differentiation or apoptosis than arsenic trioxide or ATRA alone ${ }^{13}$.

In summary, weak acids can have huge benefit in the fight against cancer. ${ }^{14-18}$ 


\section{Conflict of interest statement}

The authors declare no conflict of interests.

\section{References}

1. Zhang J, Tang M, Shi Y, et al. Appearance of somatic mutations can be subjected to the influences of inherited factors. Science. 2017. http://science.sciencemag.org/content/355/6331/1330/tab-e-letters

2. Tang M, Zhou Y, Li Y, et al. Hydrogen donors and acceptors and basic amino acids jointly contribute to carcinogenesis. Med Hypotheses. 2017;98:42-44.

3. Kadison A, Kim J, Maldonado $\mathrm{T}$, et al. Retinoid signaling directs secondary lineage selection in pancreatic organogenesis. $J$ Pediatr Surg. 2001;36(8):1150-1156.

4. Choi SH, Kang HK, Im EO, et al. Inhibition of cell growth and telomerase activity of breast cancer cells in vitro by retinoic acids. Int $J$ Oncol. 2000;17(5):971-976

5. Mervis J. Ancient remedy perform trick. Science. 1996;273 (5275):578

6. Ramaekers BLT, Riemsma R, Grimm S, et al. Arsenic trioxide for treating acute promyelocytic leukaemia: an evidence review group perspective of a NICE single technology appraisal. Pharmacoeconomics. 2019;37(7):887-894

7. Testa U., Grignani F, Samoggia P. et al. The PML/ RAR afusion protein inhibits tumor necrosis factor induced apoptosis in U397 and acute promyelolytic leukemia blasts. J Clin Invest.1998;101(10):2278

8. Chen GQ. Zhu J, Shi XG, et al. In vitro studies on cellular and molecular mechanisms of arsenic trioxide ( As2O3) in the treatment of acute promyelocytic leukemia: As2O3 induce NB4 cell apoptosis with down regulation of bcl-2 expression and modulation of PML-RAR $\alpha /$ PML proteins. Blood. 1996;88(3):1052

9. Shao W, Faneli M, Ferrara F, et al. Arsenic trioxide as an inducer of apoptosis and loss of PML/ RAR $\alpha$ protein in acute promyelocytic leukemia cells. J Natl Inst. 1998;90(2):124

10. Mathews V, George B, Lakshmi KM, et al. Single-agent arsenic trioxide in the treatment of newly diagnosed acute promyelocytic leukemia: durable remissions with minimal toxicity. Blood. 2006;107(7):2627-2632.

11. Nayak S, Shen M, Bunaciu RP, et al., Arsenic trioxide cooperates with all trans retinoic acid to enhance mitogen-activated protein kinase activation and differentiation in PML-RARalpha negative human myeloblastic leukemia cells. Leuk Lymphoma. 2010;51(9):1734-1747.

12. de Thé H, Le Bras M, Lallemand-Breitenbach V. The cell biology of disease: acute promyelocytic leukemia, arsenic, and PML bodies. J Cell Biol. 2012:198(1):11-21 
13. Gianni M, Koken M, Chelbi-Alix M, et al. Combine arsenic and retinoic acid treatm ent enhance differentiation and apoptosis in arsenic-resistant NB4 cells. Blood. 1998;91(11):4300.

14. An S, Li X, Tang M, et al., The role of acetate in the antagonism of oxalate - A potential causative molecule for heart disease and cancer death. Nat Prod Commun. 2020;15(3):1-4.

15. Wan Y, Li J, Liu Q. Vinegar production and cancer risk. Eur J Cancer Prev. 2019; 28:382.

16. Shi Y, An S, Wan Y, et al. How to best use acetic acid for the prevention of heart disease and cancer. Eur J Prev Cardiol. 2019;26:437-438.

17. An S, Wan Y, Shi Y, et al. How to choose medicinally more valuable yogurt products for the prevention of heart disease and colorectal cancer. Eur J Prev Cardiol. 2018;25:2013-2014.

18. Wan Y, Wen L, Liu Q. Who will benefit from colorectal cancer prevention measures? Eur J Cancer Prev. 2019;28(5):459-460. 